\title{
Inducible Clindamycin Resistance in Staphylococcus aureus Isolated from Clinical Samples
}

\author{
Kavitha Prabhu, Sunil Rao, Venkatakrishna Rao
}

Department of Microbiology, Yenepoya Medical College, Deralakatte, Mangalore, Karnataka, India

Address for correspondence: Dr. Kavitha, E-mail: kaavitaramesh@yahoo.co.in

\section{ABSTRACT}

Introduction: The resistance to antimicrobial agents among Staphylococci is an increasing problem. This has led to renewed interest in the usage of Macrolide-Lincosamide-Streptogramin B $\left(\mathrm{MLS}_{\mathrm{B}}\right)$ antibiotics to treat Staphylococcus aureus (S. aureus) infections. The resistance to macrolide can be mediated by $m s r A$ gene coding for efflux mechanism or via erm gene encoding for enzymes that confer inducible or constitutive resistance to $\mathrm{MLS}_{\mathrm{B}}$ antibiotics. In vitro routine tests for clindamycin susceptibility may fail to detect inducible clindamycin resistance due to erm genes resulting in treatment failure, thus necessitating the need to detect such resistance by a simple $D$ test on a routine basis.

Materials and Methods: One hundred and ninety $S$. aureus isolates were subjected to routine antibiotic susceptibility testing including oxacillin $(1 \mu \mathrm{g})$ and cefoxitin $(30 \mu \mathrm{g})$ by modified Kirby Bauer disc diffusion method. Inducible resistance to clindamycin in $S$. aureus was tested by 'D test' as per CLSI guidelines.

Results: Twenty (10\%) isolates showed inducible clindamycin resistance, 18 (9\%) showed constitutive resistance while remaining $16(8 \%)$ showed MS phenotype. Inducible resistance and constitutive resistance were found to be higher in MRSA as compared to MSSA (20\%, $16 \%$ and $6 \%, 6 \%$, respectively).

Conclusion: Clindamycin is kept as a reserve drug and is usually advocated in severe MRSA infections depending upon the antimicrobial susceptibility results. This study showed that $D$ test should be used as a mandatory method in routine disc diffusion testing to detect inducible clindamycin resistance in Staphylococci for the optimum treatment of patients.

Keywords: Clindamycin resistance, constitutive MLSB phenotype, inducible MLSB phenotype, MRSA, MS phenotype

\section{INTRODUCTION}

C taphylococcus aureus (S. aureus) is recognized as one of the most common organisms causing nosocomial and community-acquired infections in every region of the world. The increasing prevalence of methicillin resistance among Staphylococci is an increasing problem. ${ }^{[1]}$ This has led to renewed interest in the usage of MacrolideLincosamide-Streptogramin B $\left(\mathrm{MLS}_{\mathrm{B}}\right)$ antibiotics to treat S. aureus infections with clindamycin being the preferred agent due to its excellent pharmacokinetic properties. ${ }^{[2,3]}$ However, widespread use of $\mathrm{MLS}_{\mathrm{B}}$ antibiotics has led to an increase in the number of Staphylococcal strains acquiring resistance to $\mathrm{MLS}_{\mathrm{B}}$ antibiotics. ${ }^{[3,4]}$

\begin{tabular}{|c|c|}
\hline \multicolumn{2}{|c|}{ Access this article online } \\
\hline 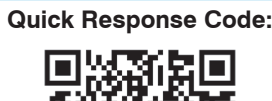 & $\begin{array}{l}\text { Website: } \\
\text { www.jlponline.org }\end{array}$ \\
\hline & $\begin{array}{l}\text { DOI: } \\
10.4103 / 0974-2727.78558\end{array}$ \\
\hline
\end{tabular}

Clindamycin resistance in Staphylococcus species can be either constitutive or inducible. ${ }^{[5]}$ The most common mechanism for such resistance is target site modification mediated by erm genes, which can be expressed either constitutively (constitutive MLS ${ }_{\text {в }}$ phenotype) or inducibly (inducible MLS $_{\mathrm{B}}$ phenotype). Strains with inducible resistance to clindamycin are difficult to detect in the routine laboratory as they appear erythromycinresistant and clindamycin sensitive in vitro when not placed adjacent to each other. In such cases, in vivo therapy with clindamycin may select constitutive erm mutants leading to clinical therapeutic failure. In case of another mechanism of resistance mediated through msr A genes i.e. efflux of antibiotic, Staphylococcal isolates appear erythromycin-resistant and clindamycin-sensitive both in vivo and in vitro and the strain do not typically become clindamycin resistant during therapy. ${ }^{[3]}$

The present study was aimed to find out the percentage of $S$. aureus having inducible clindamycin resistance $\left(\mathrm{iMLS}_{\mathrm{B}}\right)$ in our geographic area using D-test. Also, we tried to 


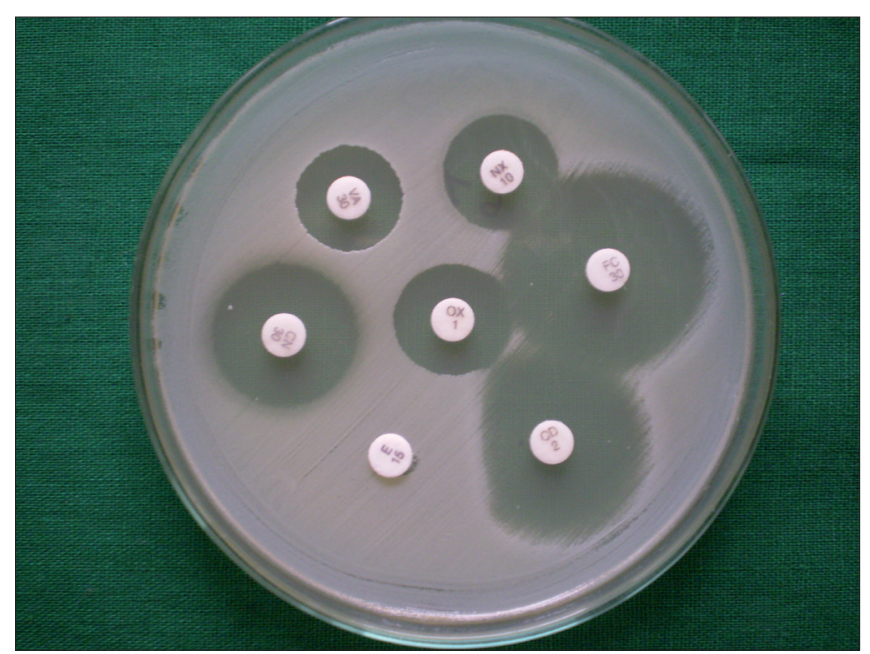

Figure 1: D-test showing inducible clindamycin resistance

ascertain the relationship between methicillin-resistant $S$. aureus (MRSA) and inducible clindamycin resistance.

\section{MATERIALS AND METHODS}

This prospective study was conducted from April 2010 to July 2010. A total of $190 \mathrm{~S}$. aureus were isolated from various clinical specimens like pus, wound swab, aspirates, blood, and sterile fluids and tested. The isolates were first identified as $S$. aureus by standard biochemical techniques ${ }^{[6]}$ and then subjected to susceptibility testing by modified Kirby Bauer's disc diffusion method on Mueller Hinton agar plates using erythromycin $(15 \mu \mathrm{g})$, norfloxacin $(5 \mu \mathrm{g})$, fusidic acid (10 $\mu \mathrm{g})$, vancomycin (30 $\mu \mathrm{g})$, clindamycin $(2 \mu \mathrm{g})$, oxacillin $(1 \mu \mathrm{g})$, and cefoxitin $(30 \mu \mathrm{g})$ as per CLSI guidelines. ${ }^{[7]}$ An inhibition zone of $10 \mathrm{~mm}$ or less around oxacillin disc and $19 \mathrm{~mm}$ or less around cefoxitin disc indicates MRSA.

Inducible resistance to clindamycin was tested by ' $\mathrm{D}$ test' as per CLSI guidelines. ${ }^{[7]}$ Briefly, erythromycin $(15 \mu \mathrm{g})$ disc was placed at a distance of $15 \mathrm{~mm}$ (edge to edge) from clindamycin $(2 \mu \mathrm{g})$ disc on a Mueller-Hinton agar plate, previously inoculated with $0.5 \mathrm{McF}$ arland standard bacterial suspensions. Following overnight incubation at $37^{\circ} \mathrm{C}$, flattening of zone (D-shaped) around clindamycin in the area between the two discs, indicated inducible clindamycin resistance [Figure 1].

Three different phenotypes were appreciated after testing and then interpreted. This interpretation was done only for erythromycin-resistant $S$. aureus strains. All the erythromycin-sensitive strains were excluded.

1. MS phenotype - Staphylococcal isolate exhibiting resistance to erythromycin (zone size $\leq 13 \mathrm{~mm}$ ) while sensitive to clindamycin (zone size $\geq 21 \mathrm{~mm}$ ) and giving circular zone of inhibition around clindamycin was labeled as having this phenotype.
2. Inducible $\mathrm{MLS}_{\mathrm{B}}\left(\mathrm{iMLS}_{\mathrm{B}}\right.$ ) phenotype - Staphylococcal isolate showing resistance to erythromycin (zone size $\leq 13 \mathrm{~mm}$ ) while being sensitive to clindamycin (zone size $\geq 21 \mathrm{~mm}$ ) and giving $\mathrm{D}$-shaped zone of inhibition around clindamycin with flattening towards erythromycin disc was labeled as having this phenotype.

3. Constitutive $\mathrm{MLS}_{\mathrm{B}}$ phenotype - this phenotype was labeled for those Staphylococcal isolates, which showed resistance to both erythromycin (zone size $\leq 13 \mathrm{~mm}$ ) and clindamycin (zone size $\leq 14 \mathrm{~mm}$ ) with circular shape of zone of inhibition if any around clindamycin.

Quality control (QC) of the erythromycin and clindamycin discs was performed with $S$. aureus ATCC25923, according to the standard disc diffusion QC procedure. Additional QC was performed with separate in-house selected $S$. aureus strains that demonstrated positive and negative $\mathrm{D}$-test reactions.

Results were tabulated and analysed statistically.

\section{RESULTS}

One hundred and ninety $S$. aureus strains were tested for susceptibility to erythromycin and other antibiotics by routine disc diffusion testing; $54(28.42 \%)$ of them were erythromycin resistant. Result of D-test analysis was shown in Table 1. Percentage of both inducible and constitutive resistance was higher amongst MRSA isolates as compared to MSSA [Table 2].

\section{DISCUSSION}

In recent times, clindamycin has become an excellent drug for some Staphylococcal infections, particularly skin and soft tissue infections and as an alternative in penicillin-allergic patients. ${ }^{[8]}$ Also, clindamycin has good oral bioavailability making it a good option for outpatient therapy and changeover after intravenous antibiotics. ${ }^{[9]}$ However, clindamycin resistance can develop in Staphylococcal isolates with inducible phenotype, and from such isolates, spontaneous constitutively resistant mutants have arisen both in vitro testing and in vivo during clindamycin therapy..$^{[1]}$ Reporting $S$. aureus as susceptible to clindamycin without checking for inducible resistance may result in institution of inappropriate clindamycin therapy. On the other hand negative result for inducible clindamycin resistance confirms clindamycin susceptibility and provides a very good therapeutic option. ${ }^{[3]}$ Since the $\mathrm{iMLS}_{\mathrm{B}}$ resistance mechanism is not recognized by using standard susceptibility test methods and its prevalence varies according to geographic location, $\mathrm{D}$-test becomes an imperative part of routine antimicrobial susceptibility 


\begin{tabular}{|c|c|c|c|}
\hline \multicolumn{4}{|c|}{$\begin{array}{l}\text { Table 1: Susceptibility to erythromycin (ERY) and } \\
\text { clindamycin (CL) among all } S \text {. aureus isolates }\end{array}$} \\
\hline \multicolumn{2}{|c|}{ Susceptibility pattern (Phenotype) } & Number of isolates & Percentage \\
\hline \multicolumn{2}{|c|}{ ERY-S, CL-S } & 136 & $71.57 \%$ \\
\hline \multicolumn{2}{|c|}{ ERY-R, CL-R (Constitutive MLS ${ }_{\mathrm{B}}$ ) } & 18 & $9.47 \%$ \\
\hline \multicolumn{2}{|c|}{ ERY-R, CL-S (D-test positive, iMLS ${ }_{\mathrm{B}}$ ) } & 20 & $10.52 \%$ \\
\hline \multicolumn{2}{|c|}{ ERY-R, CL-S (D-test negative, MS) } & 16 & $8.42 \%$ \\
\hline \multicolumn{2}{|l|}{ Total } & 190 & 100 \\
\hline \multicolumn{4}{|c|}{$\begin{array}{l}E R Y=\text { Erythromycin, } C L=C \text { lindamycin, } S=\text { Sensitive, } R=\text { Resistant, Constitutive } \\
M L S_{B}=\text { Constitutive } M^{\prime} S_{B} \text { phenotype, } \mathrm{iMLS}_{\mathrm{B}} \text { =inducible } M L S_{B} \text { phenotype, } M S=M S \\
\text { phenotype }\end{array}$} \\
\hline \multicolumn{4}{|c|}{$\begin{array}{l}\text { Table 2: Association of clindamycin resistance } \\
\text { with methicillin resistance }\end{array}$} \\
\hline \multirow{2}{*}{$\begin{array}{l}\text { Clindamycin } \\
\text { resistance }\end{array}$} & \multicolumn{2}{|c|}{ Methicillin Resistance } & \multirow{2}{*}{$\begin{array}{c}\text { Total } \\
(n=190)\end{array}$} \\
\hline & $\operatorname{MRSA}(n=60)$ & $\operatorname{MSSA}(n=130)$ & \\
\hline ERY-S, CL-S & $30(50)$ & $106(81.64)$ & $136(71.57)$ \\
\hline $\begin{array}{l}\text { ERY-R, CL-R } \\
\text { (Constitutive } \text { MLS }_{\mathrm{B}} \text { ) }\end{array}$ & $10(16.66)$ & $8(6.15)$ & $18(9.47)$ \\
\hline $\begin{array}{l}\text { ERY-R, CL-S (D-test } \\
\text { positive, iMLS } \mathrm{BLS}_{\mathrm{B}} \text { ) }\end{array}$ & $12(20)$ & $8(6.15)$ & $20(10.52)$ \\
\hline $\begin{array}{l}\text { ERY-R, CL-S (D-test } \\
\text { negative, MS) }\end{array}$ & $8(13.33)$ & $8(6.15)$ & $16(8.42)$ \\
\hline \multicolumn{4}{|c|}{$\begin{array}{l}\text { ERY=Erythromycin, } C L=\text { Clindamycin, } S=\text { Sensitive, } R=\text { Resistant, Constitutive } \\
M L S_{B}=\text { Constitutive } M L S_{B} \text { phenotype, iMLS } S_{B}=\text { inducible } \mathrm{MLS}_{\mathrm{B}} \text { phenotype, } \\
\mathrm{MS}=\mathrm{MS} \text { phenotype, } \mathrm{MRSA}=\text { Methicillin-resistant Staphylococcus aureus, } \\
\text { MSSA=Methicillin sensitive Staphylococcus aureus, Figures in parenthesis are in } \\
\text { percentage }\end{array}$} \\
\hline
\end{tabular}

test for all clinical isolates of $S$. aureus. ${ }^{[10]}$

In our study we found high percentage of erythromycinresistant $S$. aureus isolates (28.42\%). Among them 20 $(37.52 \%)$ isolates tested positive for inducible clindamycin resistance by $\mathrm{D}$-test, while rest of the isolates were negative for D-test, out of which $18(16.66 \%)$ were shown to have constitutive clindamycin resistance and $16(29.62 \%)$ showed true sensitivity to clindamycin (MS phenotype). The findings are consistent with the previous studies, ${ }^{[1]}$ and these observations suggest that had D-test not been performed, one-third of the erythromycin-resistant isolates would have been misidentified as clindamycin sensitive resulting in therapeutic failure.

It was also observed that percentages of inducible resistance and constitutive clindamycin resistance were higher amongst MRSA as compared to MSSA ((20\%, $16.66 \%$ and $6.15 \%, 6.15 \%$, respectively). This was in concordance with few of the studies reported before. ${ }^{[1]}$ Some studies have shown a very high frequency of inducible resistance MRSA. ${ }^{[4]}$ On the contrary, few studies have showed higher percentage of inducible resistance in MSSA as compared to MRSA. ${ }^{[2,13]}$

Accurate susceptibility data are important for appropriate therapy decisions. The pattern of macrolide resistance in $S$. aureus varies in different regions. Depending upon this the prescription rate will not be uniform in different regions. There is no substantial data regarding clindamycin prescription from India. It is kept as a reserve drug and is usually advocated in severe in-patient MRSA infections depending upon the antimicrobial susceptibility results. Further, by using clindamycin, use of vancomycin can be avoided. ${ }^{[10]}$ However, expression of inducible resistance to clindamycin could limit the effectiveness of this drug. ${ }^{[14]}$ So, clinical microbiology laboratories should report inducible clindamycin resistance in $S$. aureus, and $\mathrm{D}$-test can be used as a simple, auxiliary and reliable method to delineate inducible and constitutive clindamycin resistance in routine clinical laboratories.

\section{REFERENCES}

1. Yilmaz G, Aydin K, Iskender S, Caylan R, Koksal I. Detection and prevalence of inducible clindamycin resistance in staphylococci. J Med Microbiol 2007;56:342-5.

2. Delialioglu N, Aslan G, Ozturk C, Baki V, Sen S, Emekdas G. Inducible clindamycin resistance in staphylococci isolated from clinical samples. Jpn J Infect Dis 2005;58:104-6.

3. Deotale V, Mendiratta DK, Raut U, Narang P. Inducible clindamycin resistance in Staphylococcus aureus isolated from clinical samples. Indian J Med Microbiol 2010;28:124-6.

4. Ajantha GS, Kulkarni RD, Shetty J, Shubhada C, Jain P. Phenotypic detection of inducible clindamycin resistance among Staphylococcus aureus isolates by using the lower limit of recommended inter-disk distance. Indian J Pathol Microbiol 2008;51:376-8.

5. Lim HS, Lee H, Roh KH, Yum JH, Yong D, Lee K, et al. Prevalence of inducible clindamycin resistance in staphylococcal isolates at Korean tertiary care hospital. Yonsei Med J 2006;47:480-4.

6. Kloos WE, Banerman TL. Staphylococcus and Micrococcus. In: Murray PR, Baron EJ, Pfaller MA, Tenover FC, Yolken RH, editors. $7^{\text {th }}$ ed, Chapter 22. Manual of clinical microbiology. Washington DC: ASM Press; 1999. p. 264-82.

7. Clinical and laboratory standards institute. Performance standards for antimicrobial susceptibility testing; seventeenth informational supplement. Vol.2, No.1 Clinical Laboratory Standards Institute; 2007.

8. Drinkovic D, Fuller ER, Shore KP, Holland DJ, Ellis-Pegler R. Clindamycin treatment of Staphylococcus aureus expressing inducible clindamycin resistance. J Antimicrob Chemother 2001;48:315-6.

9. Laclercq R. Mechanisms of resistance to macrolides and lincosamides: Nature of resistance elements and their clinical implications. Clin Infect Dis 2002;34:482-92.

10. Gupta V, Datta P, Rani H, Chander J. Inducible clindamycin resistance in Staphylococcus aureus: A study from North India. J Postgrad Med 2009;55:176-9.

11. Ciraj AM, Vinod P, Sreejith G, Rajani K. Inducible clindamycin resistance among clinical isolates of staphylococci. Indian J Pathol Microbiol2009;52:49-51.

12. Schreckenberger PC, Ilendo E, Ristow KL. Incidence of constitutive and inducible clindamycin resistance in Staphylococcus aureus and coagulase negative staphylococci in a community and a tertiary care hospital. J Clin Microbiol 2004;42:2777-9.

13. Levin TP, Suh B, Axelrod P, Truant AL, Fekete T. Potential clindamycin resistance in clindamycin-susceptible, erythromycin-resistant Staphylococcus aureus: Report of a clinical failure. Antimicrob Agents Chemother 2005;49:1222-4.

14. Siberry GK, Tekle T, Carroll K, Dick J. Failure of clindamycin treatment of methicillin-resistant Staphylococcus aureus expressing inducible clindamycin resistance in vitro. Clin Infect Dis 2003;37:1257-60.

How to cite this article: Prabhu K, Rao S, Rao V. Inducible clindamycin resistance in Staphylococcus aureus isolated from clinical samples. J Lab Physicians 2011;3:25-7.

Source of Support: Nil. Conflict of Interest: None declared. 